\title{
Xanthogranulomatous pyelonephritis presenting as a pseudotumour
}

\author{
Mohamed Chlif, MD; Marouene Chakroun, MD; Sami Ben Rhouma, MD; Mohamed Ali Ben Chehida, MD; \\ Ahmed Sellami, MD; Mohamed Mourad Gargouri, MD; Yassine Nouira, MD
}

Urology Department, La Rabta Hospital, Tunis, Tunisia

Cite as: Can Urol Assoc J 2016;10(1-2):E36-40. http://dx.doi.org/10.5489/cuaj.3225 Published online January 14, 2016.

\section{Abstract}

Introduction: Xanthogranulomatous pyelonephritis (XGPN) is an atypical form of chronic pyelonephritis referred to as the "great imitator" because the clinical and radiological findings closely resemble other pathological entities, especially for the focal forms. Distinguishing focal XGPN from renal cancer is preoperatively difficult.

Methods: We report a total number of 12 pseudotumoural XGPN cases diagnosed and treated in our department. The aim of this study is to try to better understand the clinicopathological profile of XGPN and improve its management.

Results: The mean age of patients was 51.52 years. Gender ratio was 0.71 . An obstructive renal calculus was noticed in nine patients (75\%). Only one patient $(8.3 \%)$ presented with loin pain associated with fever, weight loss, asthenia, and increased biological inflammation markers. A bifocal mass was noticed in one case $(8.3 \%)$. The average size of the tumour was $6.58 \mathrm{~cm}$. The mass was cystic in three cases (25\%). Perinephral fat strand, thickening of Gerota's fascia, hydronephrosis, and presence of renal calculi was noticed in all solid tumour cases. XGPN was suspected in only one case $(8.3 \%)$, a percutaneous biopsy showed XGPN lesions treated by antibiotics and a double J drainage. Radical nephrectomy was performed in eight patients $(66.7 \%)$ and three patients underwent partial nephrectomy (25\%). No recurrence of XGPN has been noted.

Conclusion: Pseudotumoural XGPN is a rare benign disease of the kidney. Its treatment should be conservative. Lack of knowledge of this disease may explain the high rate of abusive nephrectomies. These data should be considered in the future.

\section{Introduction}

XGPN is an atypical form of chronic pyelonephritis characterized by the destruction of the renal parenchyma and replacement with a chronic inflammatory infiltrate of lipid- laden macrophages, known as xanthoma cells. ${ }^{1-3}$ The most common associated factors are urinary tract obstruction and infection. There are two anatomic forms of XGPN: the diffuse form, which is the most frequent, and the pseudo-tumoural form (or focal form). XGPN has been referred to as the "great imitator" because the clinical and radiological findings closely resemble other pathological entities, such as renal cell carcinoma, especially for the focal forms. Distinguishing focal XGPN from renal cancer is preoperatively difficult. Conservative treatment is advocated whenever possible.

\section{Methods}

We conducted a retrospective study on 12 pseudo-tumoural XGPN cases diagnosed and treated in our department during a 12-year period, from January 2003 to December 2014. We looked back at pathology results to identify these patients. The preoperative workup included routine biochemical and hematological tests (blood count and leukocytic formula, erythrocyte sedimentation rate (ESR), azotaemia, serum creatinine and C-reactive protein), along with urine culture. All patients underwent ultrasonography (US) and renal computed tomography (CT). The aim of this study, which reports the largest series of focal XGPN ever published, is trying to better understand the clinicopathological profile of XGPN and improve its management.

\section{Results}

Our study included 12 patients with pseudo-tumoural XGPN from a total of 44 XGPN cases diagnosed in this period; seven were female and five male (ratio: 0.71 ). The mean age was 51.52 years (range: $15-80$ ). Only one patient had a history of renal lithiasis surgery; he underwent nephrectomy because his kidney was nonfunctional. There were no XGPN lesions in pathological examination.

At diagnosis, an obstructive renal calculus was noticed in nine patients $(75 \%)$. Loin pain was the revealing symptom in 
all patients (100\%). One patient presented loin pain associated with fever, weight loss, asthenia, and anorexia. Physical exam revealed pale skin and a slight tenderness to the touch of the ipsilateral flank. No palpable flank mass was noticed.

Blood investigations showed the presence of leukocytosis (18000 cells $/ \mathrm{mm}^{3}$ ) and increased C-reactive protein (18 mg/ dl) in one patient. None had azotemia. Urine culture reports were available for all patients; four patients had growth of gram-negative organisms (two Escherichia coli and two Proteus mirabilis).

Abdominal US revealed a focal mass, located in the upper pole of the kidney in three cases $(25 \%)$, the lower pole in six cases (50\%) and the mid-part in two cases (16.7\%). A bifocal mass was noticed in one case $(8.3 \%)$, situated in both mid-part and the upper pole of the kidney. The average size of the tumour was $6.58 \mathrm{~cm}$ (range: $1.5-16 \mathrm{~cm}$ ). The mass was heterogeneous in all cases $(100 \%)$, hypo echoic in five cases $(41.7 \%)$, hyper echoic in four cases $(33.3 \%)$ and cystic in three cases (25\%).

Abdominal CT showed the same findings concerning the tumour size and its location. The mass was solid in nine cases $(75 \%)$, and cystic in three cases $(25 \%)$. The solid lesions were hypodense in four cases $(44.4 \%)$, and isodense in five cases (55.6 \%) (Fig. 1), with a slight and heterogeneous contrast enhancement in five cases (55.6\%) (Fig. 2), especially in peripheral areas. The average contrast enhancement was estimated at $21 \mathrm{HFU}$, suggesting a low vascularity of the masses. We noticed a perinephral fat strand, thickening of Gerota's fascia, hydronephrosis, or calyceal dilatation and presence of renal calculi in all solid tumour cases (100\%) (Figs. 3, 4)

Concerning the cystic lesions, the average size was 7.83 $\mathrm{cm}$. A type III of Bosniack classification was reported in two cases $(66.7 \%)$, and a type IV in one case $(33.3 \%)$. No calculi and no calyceal dilatation were noticed. Changes concerning fat and Gerota's fascia were reported in two cases $(66.7 \%)$ (Figs. 5, 6).

According to these $\mathrm{CT}$ findings, XGPN was evoked in all solid tumour cases (75\%). However, and in spite of this, we performed a percutaneous biopsy in only one patient having fever, increased biological inflammatory markers, and in radiography: calculi, dilatation, and peripheral inflammation signs. Pathological examination of the biopsy showed an infiltration by foam cells containing lipid inclusions, in association with chronic pyelonephritis lesions. An antibiotic therapy associated with a double J drainage was advocated. The ureteral stone was treated later by ureteroscopy. Followup showed the progressive decrease of the pseudotumour volume until complete recovery (Figs. 7-10).

The other eight solid masses were treated as renal cancer due to lack of clinical and biological signs suggestive of inflammation, so that renal cancer was most likely.

We advocated a surgical treatment for these eight patients, and for the three patients presenting cystic lesions.

Radical nephrectomy with lumbar incision was performed in eight patients $(66.7 \%)$. Indication for radical nephrectomy was the volume and the location of the tumour (not exophytic, nearness to the vascular pedicle). Three patients underwent partial nephrectomy (25\%), with an imperative indication to conservative treatment in one case (tumour in a solitary kidney) and a relative and elective indication in two cases (exophytic tumour). Surgery was difficult in all cases because of the adherences caused by inflammation. Three interventions required blood transfusion, with an average of 2.66 red blood cell pockets (range: 1-5). Aspirative Redon drain was removed after an average of 3.9 days (range: $2-11)$. No postoperative complications were reported in the series. After a mean follow of 34.6 months (range: $6-108$ ), no recurrences of XGPN have been noted.

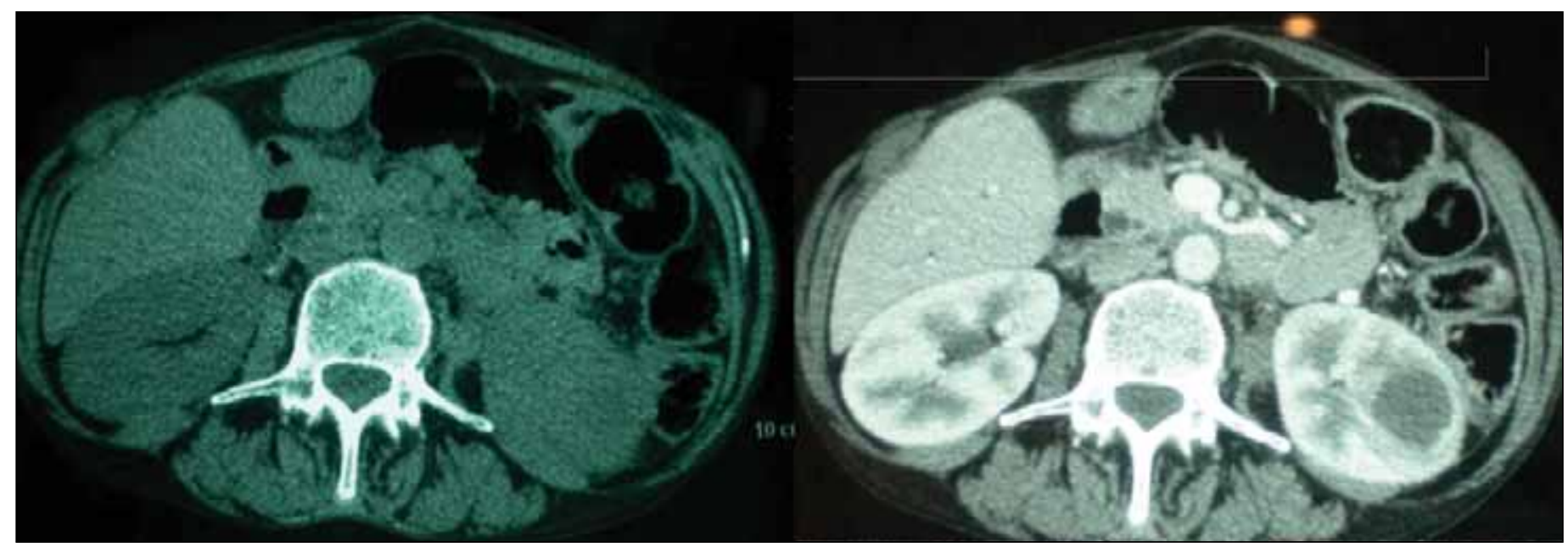

Figs.1, 2. A lower pole mass iso dense to the renal parenchyma and contrast. 


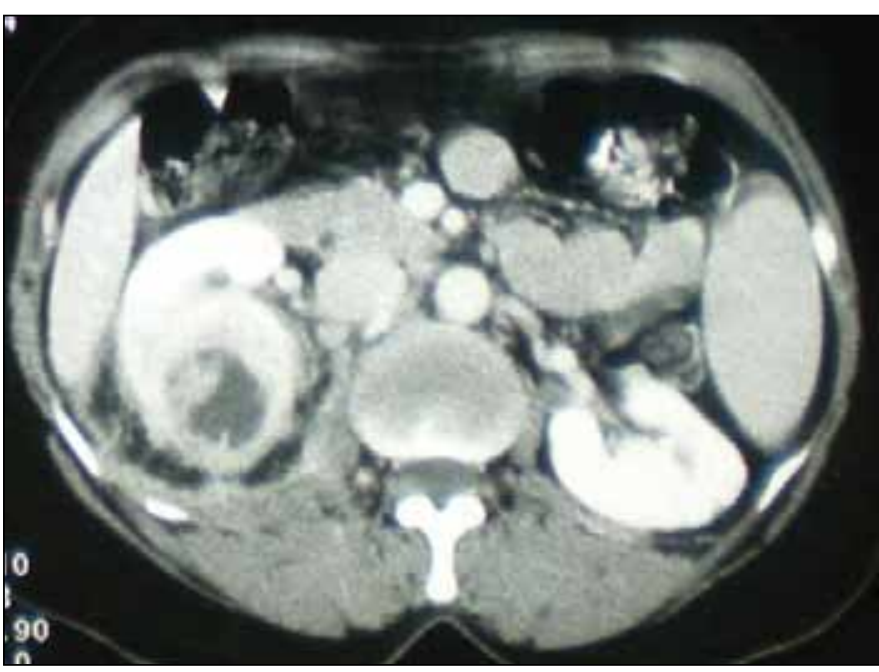

Fig. 3. Focal XGPN with peripheral fat strand and Gerota's fascia thickening.

\section{Discussion}

XGPN is a chronic granulomatous inflammation of renal parenchyma, described for the first time by Schlagenhaufen in 1916. ${ }^{4}$ In 1978, Malek and Elder classified and staged the disease. ${ }^{5}$

XGPN most frequently occurs in middle-aged women. ${ }^{1,2,6,7}$ However, some authors have noted a male predominance, ${ }^{8.9}$ or an equal exposure between genders. ${ }^{10}$ Lesions are frequently unilateral. Lithiasis, obstruction, and infection, are the main pathogenic factors. ${ }^{5,11-13}$ Two forms of XGPN have been described, a diffuse form and a pseudo-tumoural (or focal) form, which is less frequent $(15.4 \%)^{1,14,15}$

The lower pole of the kidney is the most common location of focal XGPN. In our series, $50 \%$ of these lesions involved the lower pole.

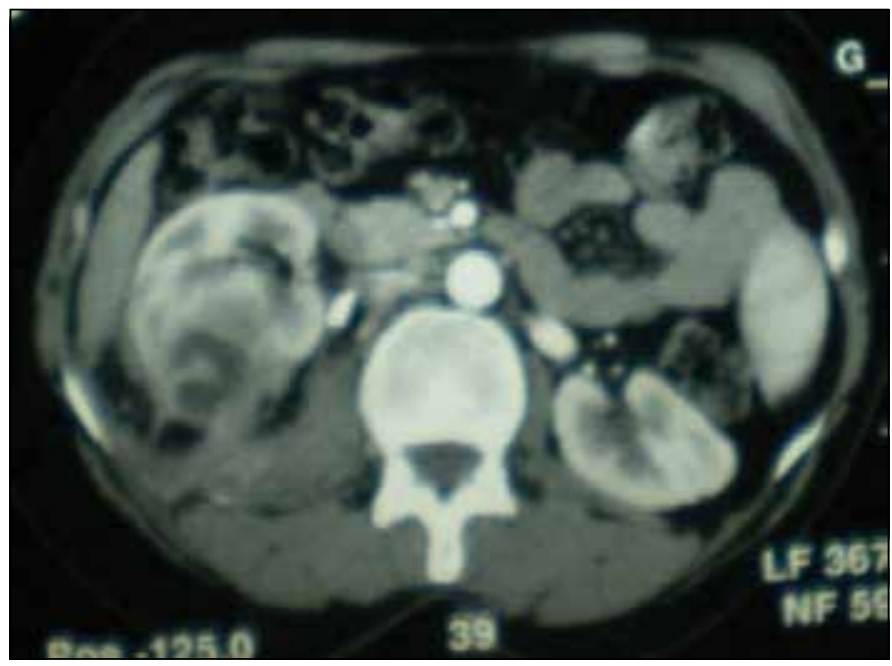

Fig. 4. Right focal XGPN with peripheral fat strand, calyceal dilatation, and a stone at the beginning of the ureter.

The most common presenting sign of focal XGPN is loin or flank pain. ${ }^{6}$ Acute fever and flank tenderness are most common in the diffuse forms. ${ }^{6,8}$ In focal forms, an intermittent fever is usually associated with anorexia, asthenia, and weight loss, mimicking a renal cancer. XGPN is often called "the great imitator."14,15

Laboratory results show a microcytic anemia, leukocytosis, thrombocytosis, and increased C-reactive protein. ${ }^{1,14}$ In our series, white blood cells and C-reactive protein rates are increased in one case $(8.3 \%)$.

Urinary culture is positive in more than $60 \%$ of cases. Escherichia coli (23.8\%) and Proteus mirabilis (14.2\%) are the most frequent organisms. ${ }^{1}$ In our series, bacteriuria is reported in $33.3 \%$ of cases (E.coli $50 \%$; P. mirabilis $50 \%$ ).

US cam identify the difference between the diffuse and the focal forms, showing an inhomogeneous solid mass
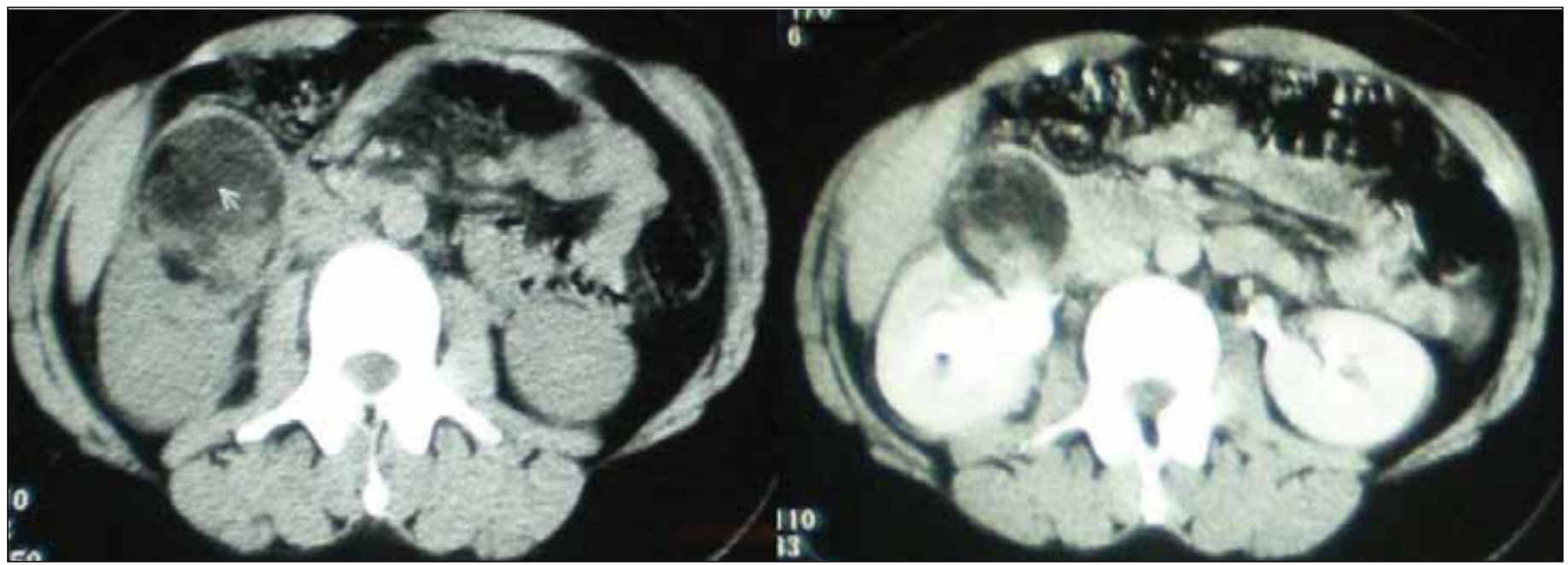

Figs 5, 6. Cystic focal XGPN and peripheral fat strand. 


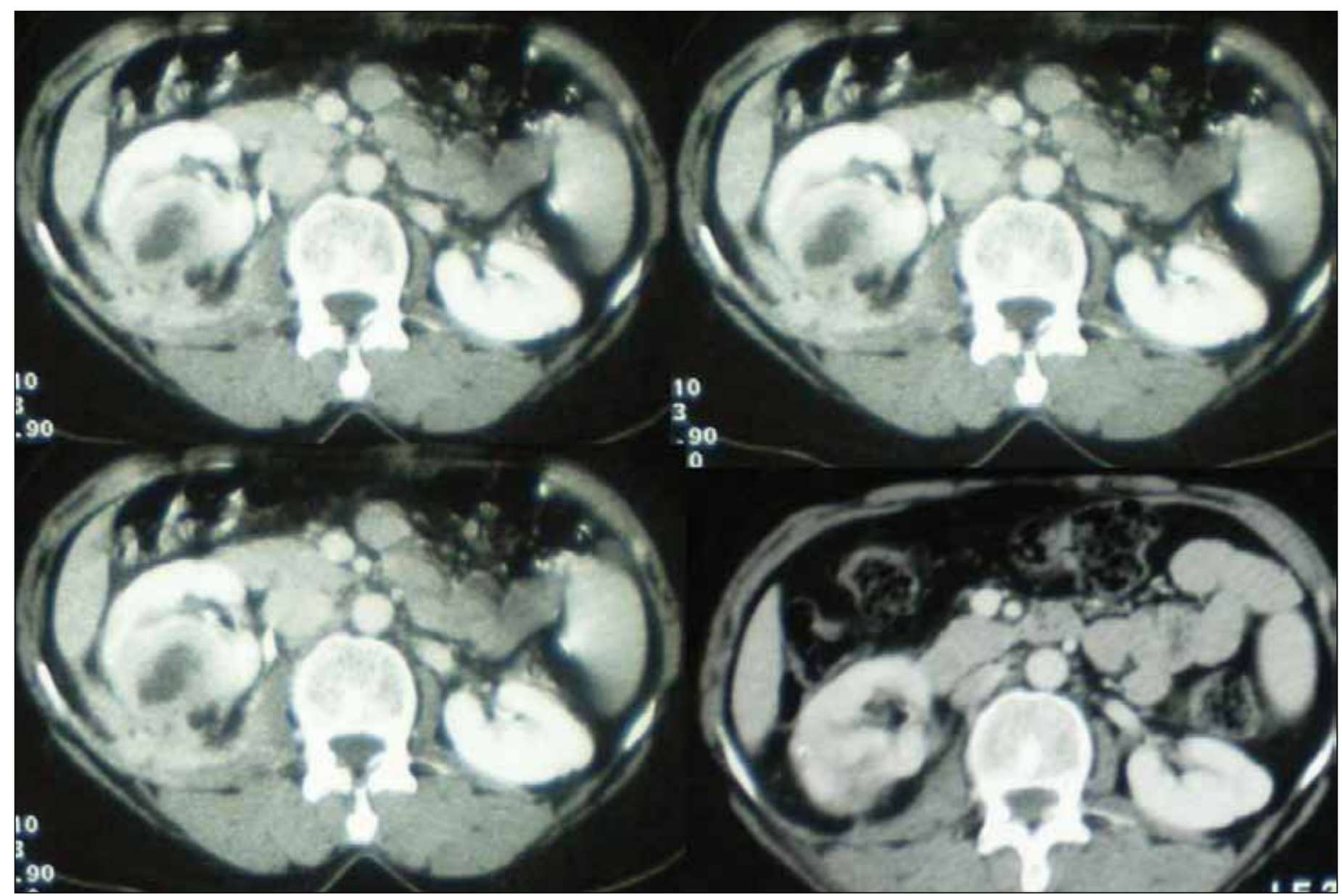

Figs. 7, 8, 9, 10. Focal XGPN (Fig. 7) and evolution at one month (Fig. 8), three months (Fig. 9), an d six months (Fig. 10) after the start of treatment.

that can be hypo or hyperechoic. US can also show pelvicalyceal dilatation and calculi. ${ }^{16-18}$ In our series, US showed cystic masses in $25 \%$ of cases.

Abdominal CT shows a renal hypodense mass $(33.3 \%$ in our series), with a slight contrast enhancement of the peripheral area $(41.7 \%$ in our series) and septa. It also shows perinephral fat strand, thickening of Gerota's Fascia, and pelvi-calyceal dilatation (75\% in our series). ${ }^{16-20}$ Cystic masses are not common in XGPN, but seen in $25 \%$ of cases in our series.

In magnetic resonance imaging (MRI), the mass has slightly low signal intensity on T2-weighted (T2W) images and is iso-intense with the renal parenchyma on T1-weighted (T1W) images. The T2W sequences are very useful for accurate differentiation of XGPN from tumours. ${ }^{17,18}$ In MRI, confusion can occur with angiomyolipoma and liposarcoma. MRI was not used in our cases.

Bilateral XGPN is extremely rare; only 10 cases of bilateral diffuse and six cases of bilateral focal XGPN have been reported in literature (none in our series). ${ }^{21,22}$

The final diagnosis should be determined by the histopathological examination findings, showing chronic pyelo- nephritis consisting of interstitial fibrosis and cellular infiltrates. It is thought that XGPN is a morphologic variant of chronic pyelonephritis, but differs from it with the abundant infiltrate of foam cells, which are thought to be macrophages containing lipids. Misinterpretation of foam cells as clear cells consistent with renal adenocarcinoma is the most important diagnostic challenge at histology. ${ }^{1,14,16}$

The management differs for diffuse and focal forms. Total nephrectomy is the standard of treatment in diffuse forms. ${ }^{23}$ In focal forms, first-line antibiotic therapy is advocated, with no recurrence reported in published studies. ${ }^{24-27}$ Medical treatment avoids a decaying surgery and offers nephronsparing. The main problem is to confirm this diagnosis and exclude renal cancer. In our series, focal XGPN was suspected in all solid cases, but was most likely in only one patient, leading to performing a percutaneous biopsy of the mass and confirming diagnosis. A conservative medical treatment was proposed to the patient, with a complete recovery and no recurrence. When focal XGPN is suspected based on clinical presentation and biologic and imaging findings, confirmation of the diagnosis by histological examination of a percutaneous renal biopsy specimen must be done. 
This biopsy can also identify the causative micro-organism and offer the possibility to give an appropriate antibiotic. Otherwise, the mass should be considered a renal cancer and treated surgically. The conservative treatment should be offered whenever possible. Its indications can be imperative when the tumour is bilateral or on solitary kidney $(7.7 \%$ in our series) ${ }^{28}$ or relative if the tumour is exophytic and removable (15.4\% in our series). ${ }^{29}$

Both radical and partial nephrectomies are technically difficult because of inflammation of tissues around kidney.

In our series, although this disease is benign, nephrectomy (total and partial) represented the only issue in $91.7 \%$ of cases. Prevention becomes very important. It consists of identifying this subpopulation of patients, treating the urinary tract infection with appropriate antibiotics, and relieving the urinary obstruction.

\section{Conclusion}

Pseudo-tumoural XGPN is a rare inflammatory disease of the kidney. The impact of obstructive lithiasis and of urinary infections is proven. The main challenge is to make correct diagnosis preoperatively in order to spare nephrons. MRI could be a great contribution when CT findings were not very evocative of cancer (only a slight peripheral enhancement). Lack of knowledge of this disease may explain the high rate of abusive nephrectomies. These data should be considered in the future.

Competing interests: The authors declare no competing financial or personal interests.

This paper has been peer-reviewed.

\section{References}

1. Li L, Parwani AV. Xanthogranulomatous pyelonephritis. Arch Pathol Lab Med 2011;135:671-4.

2. Parsons $M A$, Harris SC, Longstaff AJ, et al. Xanthogranulomatous pyelonephritis: A pathological, clinical and etiological analysis of 87 cases. Diagn Histopathol 1983;6:203-19.

3. Tilkoff-Rubin NE, Cotran RS, Rubin RH. Urinary tract infection, pyelonephritis, and reflux nephropathy. In: Brenner BM, editor. Brenner \& Rector's The Kidney. 7th ed. Philadelphia: Saunders; 2004;1554-5.

4. Korkes F, Favoretto RL, Bróglio M, et al. Xanthogranulomatous pyelonephritis: Clinical experience with 41 cases. Urology 2008;71:178-80. http://dx.doi.org/10.1016/j.urology.2007.09.026

5. Malek RS, Elder JS. Xanthogranulomatous pyelonephritis: A critical analysis of 26 cases and of the literature. J Urol 1978; 119:589-93.

6. Kim SW, Yoon BI, Ha US, et al. Xanthogranulomatous pyelonephritis: Clinical experience with 21 cases. J Infect Chemother 2013;19:1221-4. http://dx.doi.org/10.1007/s10156-013-0611-z
7. Loffroy $R$, Varbédian 0 , Guiu $B$, et al. La pyélonéphrite xanthogranulomateuse : Principaux aspects en imagerie. Prog Urol 2008;18:266-74. http://dx.doi.org/10.1016/i.purol.2008.03.015

8. Mhiri MN, Njah M, Sellami F, et al: La pyélonéphrite xanthogranulomateuse de l'enfant : A propos de huit cas. Ann. Pédiatr 1990;37:657-62.

9. Bazeed MA, Nabeeh A, Atwan N. Xanthogranulomatous pyelonephritis in bilharzial patients: A report of 25 cases. J Urol 1989:141:261-4.

10. Watson AR, Marsden HB, Lendon $M$, et al. Renal pseudotumours caused by xanthogranulomatous pyelonephritis. Arch Dis Child 1982;57:635-7. http://dx.doi.org/10.1136/adc.57.8.635

11. Levy M, Baumal R, Eddy AA. Xanthogranulomatous pyelonephritis in children: Etiology, pathogenesis, clinical, and radiologic features, management. Clin Pediatr 1994;33:360-6. http://dx.doi. org/10.1177/000992289403300609

12. D'Costa GF, Nagle SB, Wagholikar UL, et al. Xanthogranulomatous pyelonephritis in children and adultsan 8-year study. Indian J Pathol Microbiol 1990;33:224-9.

13. Sugie $S$, Tanaka T, Nishikawa A, et al. Fine-needle aspiration cytology of xanthogranulomatous pyelonephritis. Urology 1991;37: 376-9. http://dx.doi.org/10.1016/0090-4295(91)80272-9

14. Gupta S, Araya CE, Dharnidharka VR. Xanthogranulomatous pyelonephritis in pediatric patients: Case report and review of literature. J Pediatr Urol 2010;6:355-8. http://dx.doi.org/10.1016/i.jpurol.2009.09.014

15. Gupta $G$, Singh R, Kotasthane $D$, et al. Xanthogranulomatous pyelonephritis in a male child with renal vein thrombus extending into the inferior vena cava: A case report. BMC Pediatr 2010;10:47. http:// dx.doi.org/10.1186/1471-2431-10-47

16. Hendrickson RJ, Luffiyya WL, Karrer FM, et al. Xanthogranulomatous pyelonephritis. J Pediatr Surg 2006;41:15-7. http://dx.doi.org/10.1016/i.jpedsurg.2005.11.030

17. Cakmakci H, Tasdelen N, Obuz F, et al. Pediatric focal xanthogranulomatous pyelonephritis: Dynamic contrastenhanced MRI findings. Clin Imaging 2002;26:183-6. http://dx.doi.org/10.1016/S0899$7071(01) 00387-4$

18. Al-Ghazo MA, Ghalayini IF, Matalka II, et al. Xanthogranulomatous pyelonephritis: Analysis of 18 cases. Asian I Surg 2006; 29:257-61. http://dx.doi.org/10.1016/S1015-9584(09)60099-3

19. Bottalico $T$, Parks $S$, Zaslau $S$, et al. Pediatric xanthogranulomatous pyelonephritis masquerading as complex renal mass. Urology 2007;7:372:e1 1-2. http://dx.doi.org/10.1016/j.urology.2007.04.046

20. Inouye $B M$, Chiang $G$, Newbury $R O$, et al. Adolescent xanthogranulomatous pyelonephritis mimicking renal cell carcinoma on urine cytology: An atypical presenting. Urology 2013;81:885-7. http://dx.doi. org/10.1016/i.urology.2012.12.019

21. El Yacoubi S, Ziouziou I, Zizi $M$, et al. Pyélonéphrite xanthogranulomateuse bilatérale focale : à propos d'un cas. Can Urol Assoc J 2014;8(9-10):E666-9. http://dx.doi.org/10.5489/cuaj.700

22. Tsai KH, Lai MY, Shen SH. Bilateral xanthogranulomatous pyelonephritis. J Chin Med Assoc. 2008;71:3104. http://dx.doi.org/10.1016/S1726-4901(08)70128-X

23. Bingö|-Kolog $\ u$ M, Ciftçi AO, Senocak ME, et al. Xanthogranulomatous pyelonephritis in children: Diagnostic and therapeutic aspects. Eur J Pediatr Surg 2002; 12:42-8. http://dx.doi.org/10.1055/s-2002-25085

24. Rodó J, Martin ME, Salarich J. Xanthogranulomatous pyelonephritis in children: Conservative management. Eur Urol 1996; 30:498-501.

25. Shah K, Parikh $M$, Pal B, et al. Bilateral focal xanthogranulomatous pyelonephritis in a child presenting as complex cystic renal mass: A report on non-surgical treatment. Eur J Pediatr Surg 2011; 21:207-8. http://dx.doi.org/10.1055/s-0031-1271811

26. Fitouri Z, Nouira Y, Nouira K, et al. Focal xanthogranulomatous pyelonephritis: Success of conservative treatment. A case rep. Tunis Med 2008;86:912-5.

27. Reul 0 , Waltregny D, Boverie J, et al. Pyélonéphrite xanthogranulomateuse pseudo-tumourale : Diagnostic par la biopsie percutanée et succès du traitement conservateur. Prog Urol 2001;11:1274-6.

28. Kural AR, Akaydin A, Oner A, et al. Xanthogranulomatous pyelonephritis in children and adults. Br Urol 1987;59:383-5. http://dx.doi.org/10.1111/i.1464-410X.1987.tb04830.x

29. Tiguert R, Gheiler EL, Yousif R, et al. Focal xanthogranulomatous pyelonephritis presenting as renal tumour. J Urol 1998;160:117-8. http://dx.doi.org/10.1016/S0022-5347(01)63051-9

Correspondence: Dr. Marouene Chakroun; Urology Department, La Rabta Hospital, Tunis, Tunisia; cmarouene@live.fr 